\title{
Identifying MMP14 and COL12A1 as a potential combination of prognostic biomarkers in pancreatic ductal adenocarcinoma using integrated bioinformatics analysis
}

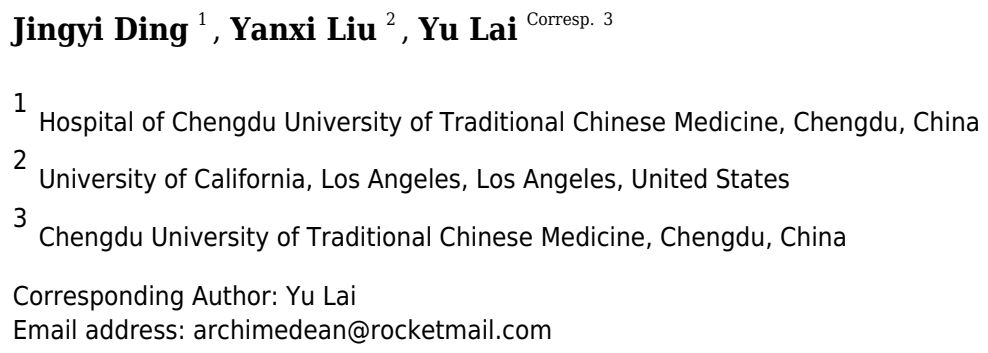

Background. Pancreatic ductal adenocarcinoma (PDAC) is a fatal malignant neoplasm. It is necessary to improve the understanding of the underlying molecular mechanisms and identify the key genes and signaling pathways involved in PDAC. Methods. The microarray datasets GSE28735 , GSE62165, and GSE91035 were downloaded from the Gene Expression Omnibus. Differentially expressed genes (DEGs) were identified by integrated bioinformatics analysis, including protein-protein interaction (PPI) network, Gene Ontology (GO) enrichment, and Kyoto Encyclopedia of Genes and Genomes (KEGG) pathway enrichment analyses. The PPI network was established using the Search Tool for the Retrieval of Interacting Genes (STRING) and Cytoscape software. GO functional annotation and KEGG pathway analyses were performed using the Database for Annotation, Visualization, and Integrated Discovery. Hub genes were validated via the Gene Expression Profiling Interactive Analysis tool (GEPIA) and the Human Protein Atlas (HPA) website. Results. A total of 263 DEGs (167 upregulated and 96 downregulated) were common to the three datasets. We used STRING and Cytoscape software to establish the PPI network and then identified key modules. From the PPI network, 225 nodes and 803 edges were selected. The most significant module, which comprised 11 DEGs, was identified using the Molecular Complex Detection plugin. The top 20 hub genes, which were filtered by the CytoHubba plugin, comprised FN1, COL1A1, COL3A1, BGN, POSTN, FBN1, COL5A2, COL12A1, THBS2, COL6A3, VCAN, CDH11, MMP14, LTBP1, IGFBP5, ALB, CXCL12, FAP, MATN3, and COL8A1. These genes were validated using The Cancer Genome Atlas (TCGA) and Genotype-Tissue Expression (GTEX) databases, and the encoded proteins were subsequently validated using the HPA website. The GO analysis results showed that the most significantly enriched biological process, cellular component, and molecular function terms among the 20 hub genes were cell adhesion, proteinaceous extracellular 
matrix, and calcium ion binding, respectively. The KEGG pathway analysis showed that the 20 hub genes were mainly enriched in ECM-receptor interaction, focal adhesion, PI3K-Akt signaling pathway, and protein digestion and absorption. These findings indicated that FBN1 and COL8A1 appear to be involved in the progression of PDAC. Moreover, patient survival analysis performed via the GEPIA using TCGA and GTEx databases demonstrated that the expression levels of COL12A1 and MMP14 were correlated with a poor prognosis in PDAC patients $(p<0.05)$. Conclusions. The results demonstrated that upregulation of MMP14 and COL12A1 is associated with poor overall survival, and these might be a combination of prognostic biomarkers in PDAC. 


\section{Manuscript Title}

2 Identifying MMP14 and COL12A1 as a potential

3 combination of prognostic biomarkers in pancreatic

4 ductal adenocarcinoma using integrated

5 bioinformatics analysis

7

Jingyi Ding ${ }^{1}$, Yanxi Liu ${ }^{2}$, Yu Lai $^{3}$

${ }^{1}$ Hospital of Chengdu University of Traditional Chinese Medicine, Chengdu, Sichuan, China

${ }^{2}$ University of California, Los Angeles, Los Angeles, California, USA

$12{ }^{3}$ School of Basic Medicine, Chengdu University of Traditional Chinese Medicine, Chengdu,

13 Sichuan, China

Corresponding Author:

$\mathrm{Yu} \mathrm{Lai}{ }^{3}$

No.1166 Liutai Avenue, Chengdu, Sichuan, 611137, China

Email address: archimedean@rocketmail.com 


\section{Abstract}

21 Background. Pancreatic ductal adenocarcinoma (PDAC) is a fatal malignant neoplasm. It is

22

23

24

25

26

27

28

29

30

31

32

33

34

35

36

37

38

39

40

41

42

43

44

45

46

47

48

49

50

51

52

53

54

55

56

57

58

59

necessary to improve the understanding of the underlying molecular mechanisms and identify the key genes and signaling pathways involved in PDAC.

Methods. The microarray datasets GSE28735, GSE62165, and GSE91035 were downloaded from the Gene Expression Omnibus. Differentially expressed genes (DEGs) were identified by integrated bioinformatics analysis, including protein-protein interaction (PPI) network, Gene Ontology (GO) enrichment, and Kyoto Encyclopedia of Genes and Genomes (KEGG) pathway enrichment analyses. The PPI network was established using the Search Tool for the Retrieval of Interacting Genes (STRING) and Cytoscape software. GO functional annotation and KEGG pathway analyses were performed using the Database for Annotation, Visualization, and Integrated Discovery. Hub genes were validated via the Gene Expression Profiling Interactive Analysis tool (GEPIA) and the Human Protein Atlas (HPA) website.

Results. A total of 263 DEGs (167 upregulated and 96 downregulated) were common to the three datasets. We used STRING and Cytoscape software to establish the PPI network and then identified key modules. From the PPI network, 225 nodes and 803 edges were selected. The most significant module, which comprised 11 DEGs, was identified using the Molecular Complex Detection plugin. The top 20 hub genes, which were filtered by the CytoHubba plugin, comprised FN1, COL1A1, COL3A1, BGN, POSTN, FBN1, COL5A2, COL12A1, THBS2, COL6A3, VCAN, CDH11, MMP14, LTBP1, IGFBP5, ALB, CXCL12, FAP, MATN3, and COL8A1. These genes were validated using The Cancer Genome Atlas (TCGA) and GenotypeTissue Expression (GTEx) databases, and the encoded proteins were subsequently validated using the HPA website. The GO analysis results showed that the most significantly enriched biological process, cellular component, and molecular function terms among the 20 hub genes were cell adhesion, proteinaceous extracellular matrix, and calcium ion binding, respectively. The KEGG pathway analysis showed that the 20 hub genes were mainly enriched in ECMreceptor interaction, focal adhesion, PI3K-Akt signaling pathway, and protein digestion and absorption. These findings indicated that $F B N 1$ and COL8A1 appear to be involved in the progression of PDAC. Moreover, patient survival analysis performed via the GEPIA using TCGA and GTEx databases demonstrated that the expression levels of COL12A1 and MMP14 were correlated with a poor prognosis in PDAC patients $(p<0.05)$.

Conclusions. The results demonstrated that upregulation of MMP14 and COL12A1 is associated with poor overall survival, and these might be a combination of prognostic biomarkers in PDAC.

\section{Introduction}

Pancreatic ductal adenocarcinoma (PDAC) is the most common malignant tumor of the pancreas and is a lethal malignancy with poor prognosis, which is in part due to its rapid progression and the lack of diagnostic and therapeutic targets. In 2018, pancreatic cancer (PC) ranked 11th among the most common cancers, with 458,918 new cases and 432,242 deaths due to PC worldwide(Bray et al. 2018). Recent work suggests that alcohol is a risk factor for PC(Go et al.

PeerJ reviewing PDF | (2020:08:52235:1:0:NEW 15 Oct 2020) 
60

61

62

63

64

65

66

67

68

69

70

71

72

73

74

75

76

77

78

79

80

81

82

83

84

85

86

87

88

89

90

91

92

93

94

95

96

97

98

2005), while both genetic and environmental factors also play a role in the development and progression of PC(Piepoli et al. 2006).

Understanding genetic alterations in the context of biological pathways can help identify specific novel biomarkers of PDAC. Previous studies identified several cancer-associated genes implicated in PDAC, including KRAS(Waters \& Der 2018), MYC(Witkiewicz et al. 2015), and $C D K N 2 A$ (Sikdar et al. 2018). It is widely accepted that the formation of stroma contributes to tumor proliferation, invasion, and metastasis(von Ahrens et al. 2017). Particularly pathognomonic for PDAC is a stromal reaction that occurs during tumor progression and extensively involves fibroblasts and the extracellular matrix (ECM)(Mahadevan \& Von Hoff 2007). Nevertheless, the precise etiology and pathogenetic mechanism of PDAC remain unclear.

Microarray technology provides high-throughput methods for quantitatively measuring the expression levels of thousands of genes simultaneously, and microarray-based gene expression profiling can filter differentially expressed genes (DEGs) and biological pathways linked to various malignant tumors. Therefore, microarray techniques are promising and efficient ways to identify candidate biomarkers involved in the pathogenesis of PDAC. The purpose of our study was to determine significant DEGs and pathways implicated in PDAC by integrated bioinformatics analysis and to provide novel insights into the progression, diagnosis, and therapeutic targets of PDAC.

\section{Materials \& Methods}

2.1 Screening database

The Gene Expression Omnibus (GEO: https://www.ncbi.nlm.nih.gov/geo/) is a public repository of high-throughput gene expression genomics datasets(Clough \& Barrett 2016). In this study, we downloaded three microarray datasets, namely, GSE28735, GSE62165, and GSE91035, from the NCBI-GEO database. The array data in GSE28735 consist of 45 matching pairs corresponding to PDAC and adjacent non-tumor tissues(Zhang et al. 2013; Zhang et al. 2012). GSE62165 includes data for 118 whole-tumor tissue and 13 control samples(Janky et al. 2016). GSE91035 incorporates data for 8 normal pancreatic and 25 PDAC tissues(Sutaria et al. 2017). Altogether, data for 188 PDAC tissues and 66 non-tumor tissues were available.

2.2 Screening of DEGs

GEO2R (https://www.ncbi.nlm.nih.gov/geo/geo2r/) is an online analysis tool that is based on the R programming language and can be used to identify DEGs that differentiate between cancer and normal samples in a GEO series(Yao \& Liu 2018). Using GEO2R, we analyzed DEGs that differentiate between PDAC and non-tumor tissue samples. An adjusted $p$-value of $<0.05$ and $|\log \mathrm{FC}|>1$ were employed as the cutoff criteria representing a significant difference. Using a data processing standard, we filtered DEGs via the Venn diagram tool at http://bioinformatics.psb.ugent.be/webtools/Venn/. A total of 263 DEGs were selected, which consisted of 167 upregulated genes and 96 downregulated genes.

2.3 Establishment of the protein-protein interaction (PPI) network

PeerJ reviewing PDF | (2020:08:52235:1:0:NEW 15 Oct 2020) 
The Search Tool for the Retrieval of Interacting Genes (STRING: http://string-db.org/) is an online application that can be used to assess DEG-encoded proteins and protein-protein interaction (PPI) networks(Szklarczyk et al. 2015). A combined score of $>0.4$ was set as the threshold.

Cytoscape software v3.2.1(Shannon et al. 2003) was utilized to visualize the PPI network, which established a new way to find potential key candidate genes and core proteins. We utilized cluster analysis via the Molecular Complex Detection (MCODE) plugin with degree cutoff $=2$, node score cutoff $=0.2, \mathrm{k}$-core $=2$, and $\max$ depth $=100$, which detected significant modules in the PPI network. To identify the hub genes, we also utilized the CytoHubba plugin, which provided a novel method of exploring significant nodes in PPI networks. These tools yield new insights into normal cellular processes, the underlying mechanisms of disease pathology, and clinical treatment.

2.4 Gene Ontology (GO) and Kyoto Encyclopedia of Genes and Genomes (KEGG) pathway analysis of DEGs

The Gene Ontology (GO) is used to perform enrichment analysis, which covers the cellular component (CC), biological process (BP), and molecular function (MF), of the selected genes(Young et al. 2010). The Kyoto Encyclopedia of Genes and Genomes (KEGG) is a database that helps to illustrate the functionalities and pathways of the selected genes(Altermann \& Klaenhammer 2005). The Database for Annotation, Visualization, and Integrated Discovery (DAVID: http://david.ncifcrf.gov/) is a public online bioinformatics database(Dennis et al. 2003) that contains information on biological functional annotations for genes and proteins. The cutoff criteria were selected on the basis of $p<0.05$. We performed enrichment of the GO terms and KEGG pathways for the candidate DEGs using DAVID.

2.5 Survival analysis of the candidate genes and validation of DEGs using TCGA and GTEx databases

Based on data for 9,736 tumors and 8,587 normal samples from The Cancer Genome Atlas (TCGA) database and the Genotype-Tissue Expression (GTEx) database, the Gene Expression Profiling Interactive Analysis tool (GEPIA: http://gepia.cancer-pku.cn/) is used to perform functions such as survival analysis, the detection of similar genes, and correlation analysis to clarify the relationships between diseases and DEGs(Tang et al. 2017).

The GEPIA was also utilized for validating and visualizing the selected DEGs using TCGA and GTEx databases(Tang et al. 2017).

2.6 Validation of expression of candidate gene-encoded proteins

The expression of proteins encoded by the PDAC candidate genes was validated using the Human Protein Atlas (HPA: https://www.proteinatlas.org/) website on the basis of spatial proteomics data and quantitative transcriptomics data (RNA-Seq) obtained from immunohistochemical analysis of tissue microarrays.

\section{Results}

\subsection{Identification of DEGs}


139

140

141

142

143

144

145

146

147

148

149

150

151

152

153

154

155

156

157

158

159

160

161

162

163

164

165

166

167

168

169

170

171

172

173

174

175

176

177

178

A total of 263 DEGs were identified from GSE28735, GSE62165, and GSE91035. There were 167 upregulated genes and 96 downregulated genes in PDAC tissues in comparison with non-tumor tissues (Fig.1) (Table 1).

\subsection{Establishment of the PPI network}

Using the STRING application and Cytoscape software, 225 nodes and 803 edges were mapped in the PPI network (Fig.2a). In association with these nodes, the whole PPI network was analyzed using the MCODE plugin, and one significant module was identified with average MCODE score $=8.6$, nodes $=11$, and edges $=43$ (Fig.2b). This significant module comprised 11 DEGs, namely, COL6A3, COL3A1, VCAN, COL5A2, COL12A1, THBS2, FBN1, POSTN, $L T B P 1, M M P 14$, and $C D H 11$. From the PPI network, the top 20 hub genes were filtered by the CytoHubba plugin using the maximal clique centrality method. Their order of sequence was as follows: FN1, COL1A1, COL3A1, BGN, POSTN, FBN1, COL5A2, COL12A1, THBS2, COL6A3, VCAN, CDH11, MMP14, LTBP1, IGFBP5, ALB, CXCL12, FAP, MATN3, and COL8A1 (Fig.2c). Via data mining, we found that the significant module and hub genes mainly consisted of upregulated genes.

3.3 GO and KEGG pathway analysis of DEGs

Functional and pathway enrichment analyses were accomplished using DAVID. GO analysis showed that the most significant module was mainly enriched in cell adhesion, extracellular matrix structural constituent, and proteinaceous extracellular matrix (Fig.3) (Table 2). Moreover, the 20 hub genes were mainly enriched in cell adhesion, endodermal cell differentiation, proteinaceous extracellular matrix, and calcium ion binding (Fig.4) (Table 3). In addition, KEGG pathway enrichment analysis demonstrated that the DEGs in the most significant module were enriched in ECM-receptor interaction (Fig.3) (Table 2) and the hub genes were mainly enriched in ECM-receptor interaction, focal adhesion, protein digestion and absorption, and PI3K-Akt signaling pathway (Fig.4) (Table 3). (If $p<0.0001$, the corresponding term was considered to be enriched.)3.4 Overall survival analysis of the top 20 hub genes

Patient survival analysis performed via the GEPIA using TCGA and GTEx databases demonstrated that the high expression levels of COL12A1 and MMP14 were correlated with an unfavorable prognosis in PDAC patients $(p<0.05)$ (Fig.5). The overall survival analysis showed that the other hub genes had no statistically significant correlations $(p>0.05)$.

3.5 Validation of DEGs using TCGA and GTEx databases

To ensure the reliability of the identification of the top 20 hub genes, we validated these via the GEPIA using TCGA and GTEx databases. Boxplots of the hub genes associated with PDAC were downloaded from the GEPIA. The results demonstrated that FN1, COL1A1, COL3A1, BGN, POSTN, FBN1, COL5A2, COL12A1, THBS2, COL6A3, VCAN, CDH11, MMP14, LTBP1, $I G F B P 5, F A P, M A T N 3$, and COL8A1 were significantly overexpressed in PDAC tissues in comparison with normal pancreatic tissues, whereas $A L B$ was underexpressed in PDAC tissues $(p<0.05)$ (Fig.6). CXCL12 was expressed in PDAC tissues, but with no statistically significant difference in expression $(p>0.05)$.

3.6 Validation of expression of candidate gene-encoded proteins 
179

180

181

182

183

184

185

186

187

188

189

190

191

192

193

194

195

196

197

198

199

200

201

202

203

204

205

206

207

208

209

210

211

212

213

214

215

216

217

218

We obtained the expression levels of proteins encoded by the 20 hub genes associated with PDAC from the HPA website. No data for proteins encoded by COL5A2, IGFBP5, and MATN3 are reported on the HPA website, and expression profiles of the other 17 genes in PDAC clinical specimens are shown in Figure 7.

The protein expressions of FN1, MMP14, COL12A1, COL3A1, COL1A1, POSTN, VCAN, $L T B P 1, F B N 1$, and $F A P$ were upregulated in PDAC tissues in comparison with normal tissues, with only $A L B$ being downregulated in PDAC tissues. COL6A3,COL8A1, CDH11, and CXCL12 were not expressed in either PDAC tissues or normal tissues, and $B G N$ and THBS2 were overexpressed in both cancer and normal tissues.

\section{Discussion}

Our study was based on GEO datasets, namely, GSE28735, GSE62165, and GSE91035. The main findings deduced from the studies used to compile GSE28735 were that dipeptidase 1 and a unique set of free fatty acids played roles in the development, progression, and prognosis of PC and might be potential targets in PDAC(Zhang et al. 2012) (Zhang et al. 2013). The study that was used to compile GSE62165 found that hepatocyte nuclear factor (HNF)-1 $\alpha$ and HNF-1 $\beta$ seem to be good candidates as tumor suppressors in PDAC(Janky et al. 2016). Another paper, which was used to compile GSE91035, concluded that an increase in the expression of the processed transcript of $H N R N P U$ was associated with a poor prognosis in PDAC(Sutaria et al. 2017).

In our study, GO analysis showed that the most significantly enriched $\mathrm{BP}, \mathrm{CC}$, and $\mathrm{MF}$ terms among the 20 hub genes were cell adhesion, proteinaceous extracellular matrix, and calcium ion binding, respectively. Cell adhesion is the attachment of a cell either to another cell or to an underlying substrate. The proteinaceous extracellular matrix provides structural support and biochemical or biomechanical cues for cells or tissues and is a structure located external to one or more cells. The ECM is a crucial factor in both promoting the progression of PDAC and inhibiting the delivery of antitumor therapy(Weniger et al. 2018).

According to the analysis of the MF terms among the hub genes, MMP14, THBS2, CDH11, $F B N 1, L T B P 1, M A T N 3$, and $V C A N$ were jointly involved in calcium ion binding, which is defined as selective and non-covalent interactions with calcium ions $\left(\mathrm{Ca}^{2+}\right) \cdot \mathrm{Ca}^{2+}$ is a ubiquitous and versatile second messenger involved in the regulation of numerous cellular functions, including gene transcription, vesicular trafficking, and cytoskeletal rearrangements(NunesHasler et al. 2020). $\mathrm{Ca}^{2+}$ and $\mathrm{Ca}^{2+}$-regulating proteins contribute to a large number of processes that are key to cancer cells, including proliferation, invasion, and cell death(Monteith et al. 2017; Prevarskaya et al. 2011). A high serum $\mathrm{Ca}^{2+}$ level is associated with a poor prognosis in PDAC(Dong et al. 2014), and cytosolic $\mathrm{Ca}^{2+}$ overload triggers apoptotic death pathways(Brini \& Carafoli 2009). It is thus reasonable that the seven abovementioned genes might regulate calcium ion binding and affect the development of PDAC. Furthermore, our study suggests that MMP14 is a promising biomarker for survival in PDAC. Considering that $\mathrm{Ca}^{2+}$ cannot be produced in cells but undergoes flux between intracellular calcium storage, cytosolic calcium signals, and the extracellular calcium pool(Yang et al. 2020), it would be reasonable to hypothesize that the 
219

220

221

222

223

224

225

226

227

228

229

230

231

232

233

234

235

236

237

238

239

240

241

242

243

244

245

246

247

248

249

250

251

252

253

254

255

256

257

overexpression of MMP14 influences calcium ion storage and thus might cause disorders of calcium homeostasis and hence contribute to an unfavorable prognosis in PDAC patients.

Matrix metalloproteinases (MMPs) are a family of calcium- and zinc-dependent membraneanchored or secreted endopeptidases that are overexpressed in various diseases, including breast cancer(Min et al. 2015). MMP14 is located in neoplastic epithelium. It is speculated that the overexpression of MMP14 alone may be sufficient to induce the development of PDAC(Shields et al. 2012). Moreover, MMP14 is overexpressed in the epithelium in invasive PC(IacobuzioDonahue et al. 2002; Shields et al. 2012), and MMP14, as an endopeptidase, can degrade various components of the ECM such as collagen, which possibly leads to metastasis of tumors(Golubkov et al. 2010). Type I collagen can induce the expression of MMP14 and TGF- $\beta 1$ in pancreatic ductal epithelial cells(Ottaviano et al. 2006), and COL1A1 encodes the major component of type I collagen. The expression of MMP14 in PDAC cells stimulates pancreatic stellate cells (PSCs) and enhances the production of type I collagen by increasing transforming growth factor- $\beta$ signaling(Krantz et al. 2011). Ottaviano et al. found that fibrosis and the expression of MMP14 in tumor specimens increased in comparison with those in normal pancreatic tissue(Ottaviano et al. 2006). These findings suggest the key role of interactions between MMP14 and type I collagen in the progression of PDAC and support MMP14 as a potential target for inhibiting fibrosis, preventing metastasis, and treating PDAC.

The KEGG pathway analysis showed that six hub genes, namely, COL1A1, COL3A1, COL5A2, COL6A3, FN1, and THBS2, were significantly associated with ECM-receptor interactions, focal adhesion, and the phosphatidylinositol-3-kinase-protein kinase B (PI3K-Akt) signaling pathway. In addition, collagen-encoding genes, including COL1A1, COL $3 A 1$, and $C O L 5 A 2$, were also enriched in protein digestion and absorption and platelet activation.

ECM-receptor interactions play important roles in the processes of cell shedding, adhesion, degradation, migration, differentiation, hyperplasia, and apoptosis(Bao et al. 2019). PSCs secrete several ECM proteins, including collagen, fibronectin, fibulin-2, and laminin, as well as hyaluronan (Hall et al. 2019). Moreover, COL1A1 and COL3A1 were significantly downregulated in PC $(p<0.0001)$ after treatment with gemcitabine in combination with EC359(Hall et al. 2019). The gene COL1A1 encodes the pro-alpha 1 chain of type I collagen, which is closely associated with MMP14. COL $3 A 1$ was found to encode a major structural component of hollow organs such as large blood vessels, the uterus and bowel, and tissues that must withstand stretching(Kuivaniemi \& Tromp 2019). As an important molecule, COL5A2 is associated with remodeling of the ECM and is differentially expressed between in situ ductal carcinoma and invasive ductal carcinoma(Vargas et al. 2012). The alpha 3 chain of type VI collagen is mainly present in the desmoplastic stroma in PDAC, with large deposits between the sites of stromal fatty infiltration and around the malignant ducts(Arafat et al. 2011), and the circulating form of this protein has potential clinical significance in the diagnosis of pancreatic malignancy(Kang et al. 2014). FN1 encodes a collagen-associated protein that has been identified as a potential biomarker of an unfavorable prognosis in PDAC(Hu et al. 2018). THBS2 
258

259

260

261

262

263

264

265

266

267

268

269

270

271

272

273

274

275

276

277

278

279

280

281

282

283

284

285

286

287

288

289

290

291

292

293

294

295

296

297

appears in the early stages of PDAC and hence has great potential for the diagnosis of PDAC, with 98\% specificity(Kim et al. 2017).

At points of ECM-cell contact, specialized structures are formed, which are termed focal adhesions. Some components of focal adhesions contribute to cell migration in PDAC and participate in structural links between the actin cytoskeleton and membrane receptors, whereas others are signaling molecules(Manoli et al. 2019).

The PI3K-Akt signaling pathway regulates fundamental cellular functions, including transcription, translation, proliferation, growth, and survival. Accumulating evidence has implied that the PI3K-Akt signaling pathway promotes malignant processes of PDAC cells, including proliferation, angiogenesis, metastasis, suppression of apoptosis, and chemoresistance, and targeting the PI3K-Akt signaling pathway has been a potential therapeutic strategy for the treatment of PC(Ebrahimi et al. 2017).

In $\mathrm{PC}$, both exocrine and endocrine functions are abnormal, which profoundly influences the secretion of proteases, and hence protein digestion and absorption is a prominent metabolic change(Gilliland et al. 2017). Platelet activation facilitates the P-selectin- and integrin-dependent accumulation of cancer cell microparticles and promotes tumor growth and metastasis(Mezouar et al. 2015). However, the effect of collagen-mediated platelet activation on the progression of PDAC needs further investigation.

Collagens are centrally involved in the formation of fibrillar and microfibrillar networks of the ECM and basement membranes, as well as other structures of the ECM(Gelse et al. 2003). We further found that the collagen family is closely associated with PDAC. Interestingly, Wang and Li also found that the collagen family and FN1 have an influence on PC via data mining using a different gene set (GSE15471)(Wang \& Li 2015). As we have done, they suggested that FN1, together with $C O L 1 A 1, C O L 3 A 1$, and COL5A2, may be key molecules in the development and progression of PDAC owing to their involvement in ECM-receptor interactions and focal adhesion pathways. These DEGs were also identified in our study. Furthermore, we found that $C O L 12 A 1$ and $C O L 6 A 3$ are probably also key DEGs that influence PDAC, which differs from the results of Wang and Li. Although the specific relationship between COL12A1 and PDAC has not been reported, our findings also suggest that $C O L 12 \mathrm{Al}$ is a potential prognostic biomarker in patients with PDAC.

We also found that $F B N 1$ and $C O L 8 A 1$ appear to be involved in the progression of PDAC. FBN1 encodes a structural component of the microfibrils of the ECM that have diameters of 10$12 \mathrm{~nm}$, which impart both regulatory and structural properties to load-bearing connective tissues(Lee et al. 2004). The silencing of FBN1 inhibits the proliferative, migratory, and invasive activities of gastric cancer cells, whereas upregulation of the expression of FBN1 has the opposite effect(Yang et al. 2017). COL8A1 encodes a macromolecular component of the subendothelium(Xu et al. 2001). It is suggested that COL8A1 may be associated with malignant processes of hepatocarcinoma(Zhao et al. 2009) and the progression and prognosis of human colon adenocarcinoma(Shang et al. 2018).

\section{Conclusions}


298

299

300

301

302

303

304

305

306

307

308

309

310

311

312

313

314

315

316

317

318

319

320

321

322

323

324

325

326

327

328

329

330

331

332

333

334

335

336

337

338

339

340

341

342

343

In conclusion, we screened the top 20 hub genes (FN1, COL1A1, COL3A1, BGN, POSTN, FBN1, COL5A2, COL12A1, THBS2, COL6A3, VCAN, CDH11, MMP14, LTBP1, IGFBP5, ALB, $C X C L 12, F A P, M A T N 3$, and $C O L 8 A 1)$ and the related enriched functions or pathways, which regulate the progression and metastatic invasion of PDAC, as well as overall survival. The results demonstrate that the upregulation of MMP14 and COL12A1 in PDAC is closely associated with poor overall survival, that these might be a potential combination of prognostic biomarkers in patients with PDAC, and that FBN1 and COL8A1 might be biomarkers of PDAC. In brief, our study increases the understanding of the potential critical genes and related pathways that participate in the pathogenesis of PDAC.

\section{Acknowledgements}

There are no acknowledgements.

\section{References}

Altermann E, and Klaenhammer TR. 2005. PathwayVoyager: pathway mapping using the Kyoto Encyclopedia of Genes and Genomes (KEGG) database. BMC Genomics 6:60. 10.1186/1471-2164-6-60

Arafat H, Lazar M, Salem K, Chipitsyna G, Gong Q, Pan TC, Zhang RZ, Yeo CJ, and Chu ML. 2011. Tumor-specific expression and alternative splicing of the COL6A3 gene in pancreatic cancer. Surgery 150:306-315. 10.1016/j.surg.2011.05.011

Bao Y, Wang L, Shi L, Yun F, Liu X, Chen Y, Chen C, Ren Y, and Jia Y. 2019. Transcriptome profiling revealed multiple genes and ECM-receptor interaction pathways that may be associated with breast cancer. Cell Mol Biol Lett 24:38. 10.1186/s11658-019-0162-0

Bray F, Ferlay J, Soerjomataram I, Siegel RL, Torre LA, and Jemal A. 2018. Global cancer statistics 2018: GLOBOCAN estimates of incidence and mortality worldwide for 36 cancers in 185 countries. CA Cancer J Clin 68:394-424. 10.3322/caac.21492

Brini M, and Carafoli E. 2009. Calcium pumps in health and disease. Physiol Rev 89:1341-1378. 10.1152/physrev.00032.2008

Clough E, and Barrett T. 2016. The Gene Expression Omnibus Database. Methods Mol Biol 1418:93-110. 10.1007/978-1-4939-3578-9_5

Dennis G, Jr., Sherman BT, Hosack DA, Yang J, Gao W, Lane HC, and Lempicki RA. 2003. DAVID: Database for Annotation, Visualization, and Integrated Discovery. Genome Biol 4:P3.

Dong Q, Zhang Y, Yang XH, Jing W, Zheng LQ, Liu YP, Qu XJ, and Li Z. 2014. Serum calcium level used as a prognostic predictor in patients with resectable pancreatic ductal adenocarcinoma. Clin Res Hepatol Gastroenterol 38:639-648. 10.1016/j.clinre.2014.01.012

Ebrahimi S, Hosseini M, Shahidsales S, Maftouh M, Ferns GA, Ghayour-Mobarhan M, Hassanian SM, and Avan A. 2017. Targeting the Akt/PI3K Signaling Pathway as a Potential Therapeutic Strategy for the Treatment of Pancreatic Cancer. Curr Med Chem 24:1321-1331. 10.2174/0929867324666170206142658

Gelse K, Poschl E, and Aigner T. 2003. Collagens--structure, function, and biosynthesis. Adv Drug Deliv Rev 55:1531-1546. 10.1016/j.addr.2003.08.002

Gilliland TM, Villafane-Ferriol N, Shah KP, Shah RM, Tran Cao HS, Massarweh NN, Silberfein EJ, Choi EA, Hsu C, McElhany AL, Barakat O, Fisher W, and Van Buren G. 2017. Nutritional and Metabolic Derangements in Pancreatic Cancer and Pancreatic Resection. Nutrients 9. 10.3390/nu9030243 
344

345

346

347

348

349

350

351

352

353

354

355

356

357

358

359

360

361

362

363

364

365

366

367

368

369

370

371

372

373

374

375

376

377

378

379

380

381

382

383

384

385

386

387

388

389

390

391

392

393

394

Go VL, Gukovskaya A, and Pandol SJ. 2005. Alcohol and pancreatic cancer. Alcohol 35:205211. 10.1016/j.alcohol.2005.03.010

Golubkov VS, Chekanov AV, Cieplak P, Aleshin AE, Chernov AV, Zhu W, Radichev IA, Zhang D, Dong PD, and Strongin AY. 2010. The Wnt/planar cell polarity protein-tyrosine kinase-7 (PTK7) is a highly efficient proteolytic target of membrane type-1 matrix metalloproteinase: implications in cancer and embryogenesis. J Biol Chem 285:3574035749. 10.1074/jbc.M110.165159

Hall BR, Cannon A, Thompson C, Santhamma B, Chavez-Riveros A, Bhatia R, Nair HB, Nickisch K, Batra SK, and Kumar S. 2019. Utilizing cell line-derived organoids to evaluate the efficacy of a novel LIFR-inhibitor, EC359 in targeting pancreatic tumor stroma. Genes Cancer 10:1-10. 10.18632/genesandcancer.184

Hu D, Ansari D, Pawlowski K, Zhou Q, Sasor A, Welinder C, Kristl T, Bauden M, Rezeli M, Jiang Y, Marko-Varga G, and Andersson R. 2018. Proteomic analyses identify prognostic biomarkers for pancreatic ductal adenocarcinoma. Oncotarget 9:9789-9807. 10.18632/oncotarget.23929

lacobuzio-Donahue CA, Ryu B, Hruban RH, and Kern SE. 2002. Exploring the host desmoplastic response to pancreatic carcinoma: gene expression of stromal and neoplastic cells at the site of primary invasion. Am J Pathol 160:91-99. 10.1016/S00029440(10)64353-2

Janky R, Binda MM, Allemeersch J, Van den Broeck A, Govaere O, Swinnen JV, Roskams T, Aerts S, and Topal B. 2016. Prognostic relevance of molecular subtypes and master regulators in pancreatic ductal adenocarcinoma. BMC Cancer 16:632. 10.1186/s12885016-2540-6

Kang CY, Wang J, Axell-House D, Soni P, Chu ML, Chipitsyna G, Sarosiek K, Sendecki J, Hyslop T, Al-Zoubi M, Yeo CJ, and Arafat HA. 2014. Clinical significance of serum COL6A3 in pancreatic ductal adenocarcinoma. J Gastrointest Surg 18:7-15. 10.1007/s11605-013-2326-y

Kim J, Bamlet WR, Oberg AL, Chaffee KG, Donahue G, Cao XJ, Chari S, Garcia BA, Petersen GM, and Zaret KS. 2017. Detection of early pancreatic ductal adenocarcinoma with thrombospondin-2 and CA19-9 blood markers. Sci Transl Med 9. 10.1126/scitransImed.aah5583

Krantz SB, Shields MA, Dangi-Garimella S, Cheon EC, Barron MR, Hwang RF, Rao MS, Grippo PJ, Bentrem DJ, and Munshi HG. 2011. MT1-MMP cooperates with Kras(G12D) to promote pancreatic fibrosis through increased TGF-beta signaling. Mol Cancer Res 9:1294-1304. 10.1158/1541-7786.MCR-11-0023

Kuivaniemi H, and Tromp G. 2019. Type III collagen (COL3A1): Gene and protein structure, tissue distribution, and associated diseases. Gene 707:151-171. 10.1016/j.gene.2019.05.003

Lee SS, Knott V, Jovanovic J, Harlos K, Grimes JM, Choulier L, Mardon HJ, Stuart DI, and Handford PA. 2004. Structure of the integrin binding fragment from fibrillin-1 gives new insights into microfibril organization. Structure 12:717-729. 10.1016/j.str.2004.02.023

Mahadevan D, and Von Hoff DD. 2007. Tumor-stroma interactions in pancreatic ductal adenocarcinoma. Mol Cancer Ther 6:1186-1197. 10.1158/1535-7163.MCT-06-0686

Manoli S, Coppola S, Duranti C, Lulli M, Magni L, Kuppalu N, Nielsen N, Schmidt T, Schwab A, Becchetti A, and Arcangeli A. 2019. The Activity of Kv 11.1 Potassium Channel Modulates F-Actin Organization During Cell Migration of Pancreatic Ductal Adenocarcinoma Cells. Cancers (Basel) 11. 10.3390/cancers11020135

Mezouar S, Darbousset R, Dignat-George F, Panicot-Dubois L, and Dubois C. 2015. Inhibition of platelet activation prevents the P-selectin and integrin-dependent accumulation of cancer cell microparticles and reduces tumor growth and metastasis in vivo. Int $J$ Cancer 136:462-475. 10.1002/ijc.28997

PeerJ reviewing PDF | (2020:08:52235:1:0:NEW 15 Oct 2020) 
395

396

397

398

399

400

401

402

403

404

405

406

407

408

409

410

411

412

413

414

415

416

417

418

419

420

421

422

423

424

425

426

427

428

429

430

431

432

433

434

435

436

437

438

439

440

441

442

443

444

Min K, Ji B, Zhao M, Ji T, Chen B, Fang X, and Ma Q. 2015. Development of a Radiolabeled Peptide-Based Probe Targeting MT1-MMP for Breast Cancer Detection. PLoS One 10:e0139471. 10.1371/journal.pone.0139471

Monteith GR, Prevarskaya N, and Roberts-Thomson SJ. 2017. The calcium-cancer signalling nexus. Nat Rev Cancer 17:367-380. 10.1038/nrc.2017.18

Nunes-Hasler P, Kaba M, and Demaurex N. 2020. Molecular Mechanisms of Calcium Signaling During Phagocytosis. Adv Exp Med Biol 1246:103-128. 10.1007/978-3-030-40406-2_7

Ottaviano AJ, Sun L, Ananthanarayanan V, and Munshi HG. 2006. Extracellular matrixmediated membrane-type 1 matrix metalloproteinase expression in pancreatic ductal cells is regulated by transforming growth factor-beta1. Cancer Res 66:7032-7040. 10.1158/0008-5472.CAN-05-4421

Piepoli A, Gentile A, Valvano MR, Barana D, Oliani C, Cotugno R, Quitadamo M, Andriulli A, and Perri F. 2006. Lack of association between UGT1A7, UGT1A9, ARP, SPINK1 and CFTR gene polymorphisms and pancreatic cancer in Italian patients. World $J$ Gastroenterol 12:6343-6348. 10.3748/wjg.v12.i39.6343

Prevarskaya N, Skryma R, and Shuba Y. 2011. Calcium in tumour metastasis: new roles for known actors. Nat Rev Cancer 11:609-618. 10.1038/nrc3105

Shang J, Wang F, Chen P, Wang X, Ding F, Liu S, and Zhao Q. 2018. Co-expression Network Analysis Identified COL8A1 Is Associated with the Progression and Prognosis in Human Colon Adenocarcinoma. Dig Dis Sci 63:1219-1228. 10.1007/s10620-018-4996-5

Shannon P, Markiel A, Ozier O, Baliga NS, Wang JT, Ramage D, Amin N, Schwikowski B, and Ideker T. 2003. Cytoscape: a software environment for integrated models of biomolecular interaction networks. Genome Res 13:2498-2504. 10.1101/gr.1239303

Shields MA, Dangi-Garimella S, Redig AJ, and Munshi HG. 2012. Biochemical role of the collagen-rich tumour microenvironment in pancreatic cancer progression. Biochem $\mathrm{J}$ 441:541-552. 10.1042/BJ20111240

Sikdar N, Saha G, Dutta A, Ghosh S, Shrikhande SV, and Banerjee S. 2018. Genetic Alterations of Periampullary and Pancreatic Ductal Adenocarcinoma: An Overview. Curr Genomics 19:444-463. 10.2174/1389202919666180221160753

Sutaria DS, Jiang J, Azevedo-Pouly ACP, Lee EJ, Lerner MR, Brackett DJ, Vandesompele J, Mestdagh P, and Schmittgen TD. 2017. Expression Profiling Identifies the Noncoding Processed Transcript of HNRNPU with Proliferative Properties in Pancreatic Ductal Adenocarcinoma. Noncoding RNA 3. 10.3390/ncrna3030024

Szklarczyk D, Franceschini A, Wyder S, Forslund K, Heller D, Huerta-Cepas J, Simonovic M, Roth A, Santos A, Tsafou KP, Kuhn M, Bork P, Jensen LJ, and von Mering C. 2015. STRING v10: protein-protein interaction networks, integrated over the tree of life. Nucleic Acids Res 43:D447-452. 10.1093/nar/gku1003

Tang Z, Li C, Kang B, Gao G, Li C, and Zhang Z. 2017. GEPIA: a web server for cancer and normal gene expression profiling and interactive analyses. Nucleic Acids Res 45:W98W102. 10.1093/nar/gkx247

Vargas AC, McCart Reed AE, Waddell N, Lane A, Reid LE, Smart CE, Cocciardi S, da Silva L, Song S, Chenevix-Trench G, Simpson PT, and Lakhani SR. 2012. Gene expression profiling of tumour epithelial and stromal compartments during breast cancer progression. Breast Cancer Res Treat 135:153-165. 10.1007/s10549-012-2123-4

von Ahrens D, Bhagat TD, Nagrath D, Maitra A, and Verma A. 2017. The role of stromal cancerassociated fibroblasts in pancreatic cancer. J Hematol Oncol 10:76. 10.1186/s13045017-0448-5

Wang Y, and Li Y. 2015. Analysis of molecular pathways in pancreatic ductal adenocarcinomas with a bioinformatics approach. Asian Pac J Cancer Prev 16:2561-2567. 10.7314/apjcp.2015.16.6.2561

Peer) reviewing PDF | (2020:08:52235:1:0:NEW 15 Oct 2020) 
445

446

447

448

449

450

451

452

453

454

455

456

457

458

459

460

461

462

463

464

465

466

467

468

469

470

471

472

473

474

475

476

477

478

Waters AM, and Der CJ. 2018. KRAS: The Critical Driver and Therapeutic Target for Pancreatic Cancer. Cold Spring Harb Perspect Med 8. 10.1101/cshperspect.a031435

Weniger M, Honselmann KC, and Liss AS. 2018. The Extracellular Matrix and Pancreatic Cancer: A Complex Relationship. Cancers (Basel) 10. 10.3390/cancers10090316

Witkiewicz AK, McMillan EA, Balaji U, Baek G, Lin WC, Mansour J, Mollaee M, Wagner KU, Koduru P, Yopp A, Choti MA, Yeo CJ, McCue P, White MA, and Knudsen ES. 2015. Whole-exome sequencing of pancreatic cancer defines genetic diversity and therapeutic targets. Nat Commun 6:6744. 10.1038/ncomms7744

Xu R, Yao ZY, Xin L, Zhang Q, Li TP, and Gan RB. 2001. NC1 domain of human type VIII collagen (alpha 1) inhibits bovine aortic endothelial cell proliferation and causes cell apoptosis. Biochem Biophys Res Commun 289:264-268. 10.1006/bbrc.2001.5970

Yang D, Zhao D, and Chen X. 2017. MiR-133b inhibits proliferation and invasion of gastric cancer cells by up-regulating FBN1 expression. Cancer Biomark 19:425-436. 10.3233/CBM-160421

Yang Z, Yue Z, Ma X, and Xu Z. 2020. Calcium Homeostasis: A Potential Vicious Cycle of Bone Metastasis in Breast Cancers. Front Oncol 10:293. 10.3389/fonc.2020.00293

Yao S, and Liu T. 2018. Analysis of differential gene expression caused by cervical intraepithelial neoplasia based on GEO database. Oncol Lett 15:8319-8324. 10.3892/ol.2018.8403

Young MD, Wakefield MJ, Smyth GK, and Oshlack A. 2010. Gene ontology analysis for RNAseq: accounting for selection bias. Genome Biol 11:R14. 10.1186/gb-2010-11-2-r14

Zhang G, He P, Tan H, Budhu A, Gaedcke J, Ghadimi BM, Ried T, Yfantis HG, Lee DH, Maitra A, Hanna N, Alexander HR, and Hussain SP. 2013. Integration of metabolomics and transcriptomics revealed a fatty acid network exerting growth inhibitory effects in human pancreatic cancer. Clin Cancer Res 19:4983-4993. 10.1158/1078-0432.CCR-13-0209

Zhang G, Schetter A, He P, Funamizu N, Gaedcke J, Ghadimi BM, Ried T, Hassan R, Yfantis HG, Lee DH, Lacy C, Maitra A, Hanna N, Alexander HR, and Hussain SP. 2012. DPEP1 inhibits tumor cell invasiveness, enhances chemosensitivity and predicts clinical outcome in pancreatic ductal adenocarcinoma. PLoS One 7:e31507. 10.1371/journal.pone.0031507

Zhao Y, Jia L, Mao X, Xu H, Wang B, and Liu Y. 2009. siRNA-targeted COL8A1 inhibits proliferation, reduces invasion and enhances sensitivity to $D$-limonence treatment in hepatocarcinoma cells. IUBMB Life 61:74-79. 10.1002/iub.151

PeerJ reviewing PDF | (2020:08:52235:1:0:NEW 15 Oct 2020) 


\section{Figure 1}

Venn diagram

Identification of differentially expressed genes (DEGs) from GSE28735, GSE62165, and GSE91035. The different colored areas represent the different datasets, and a total of 263 DEGs were common to all three datasets. 


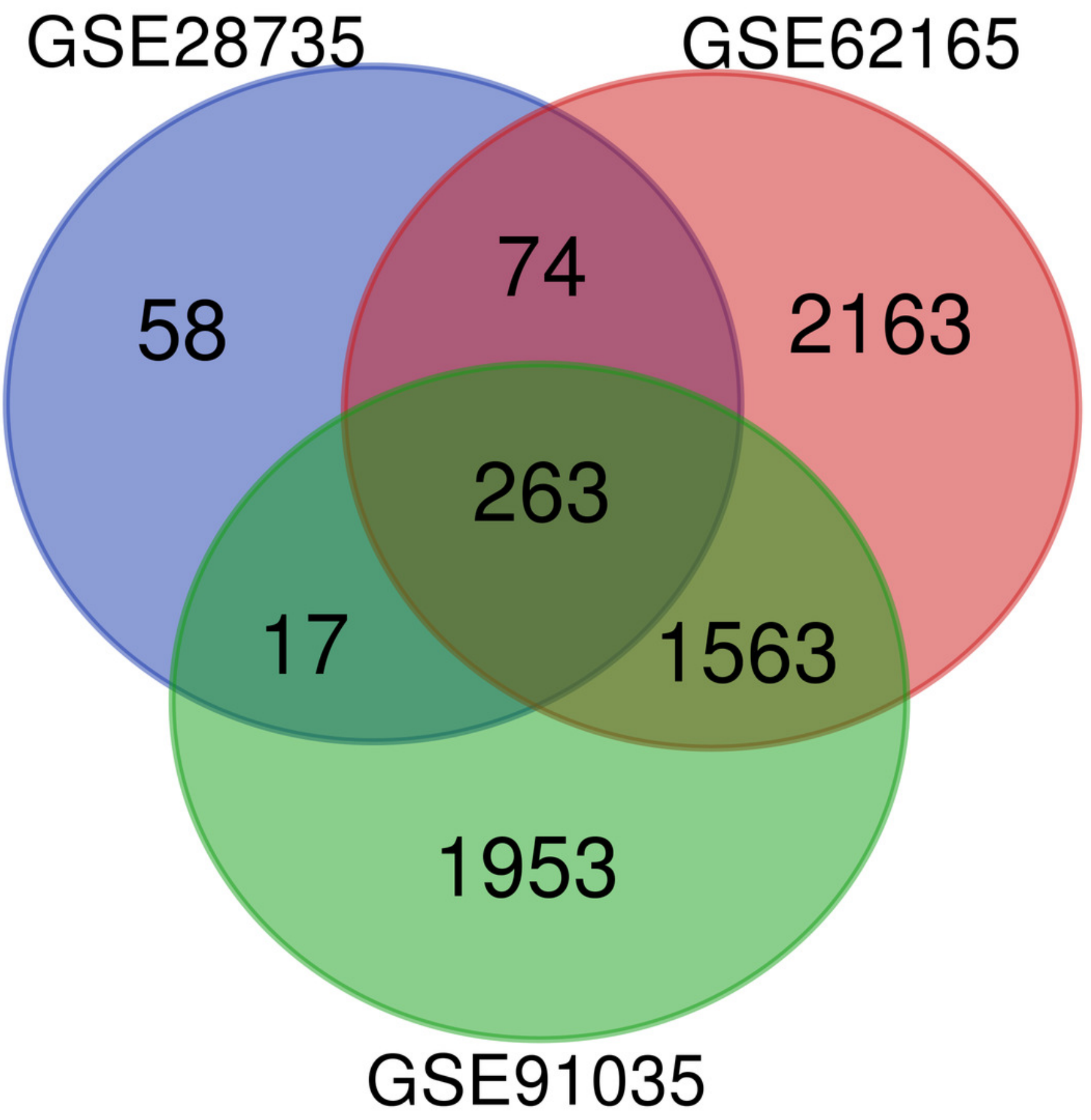


Figure 2

Protein-protein interaction (PPI) network of DEGs.

(A) PPI network of 263 DEGs in PDAC tissues. Red nodes represent upregulated genes, whereas blue nodes represent downregulated genes. (B) Significant module identified from PPI network via the Molecular Complex Detection plugin. This module consisted of upregulated genes. (C) Top 20 hub genes filtered using CytoHubba plugin. Nodes shown in darker colors were found to have higher significance. Red represents the highest significance, followed by orange, whereas yellow represents the lowest significance. 

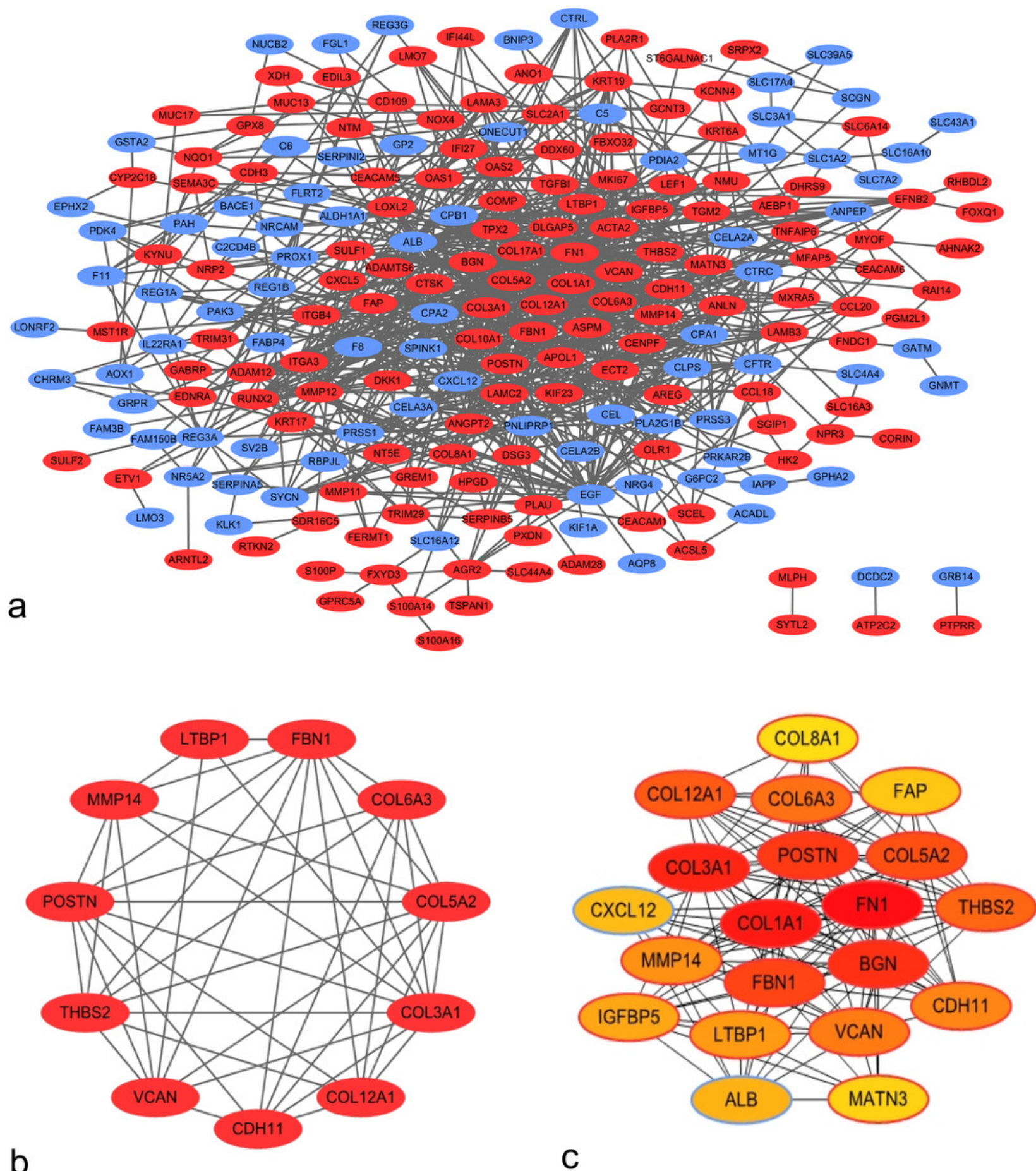

C 


\section{Figure 3}

Results of Gene Ontology (GO) and Kyoto Encyclopedia of Genes and Genomes (KEGG) pathway analyses of the most significant module.

The blue color represents biological process (BP), the gray color represents molecular function (MF), the green color represents cellular component (CC), and the orange color represents KEGG pathways.

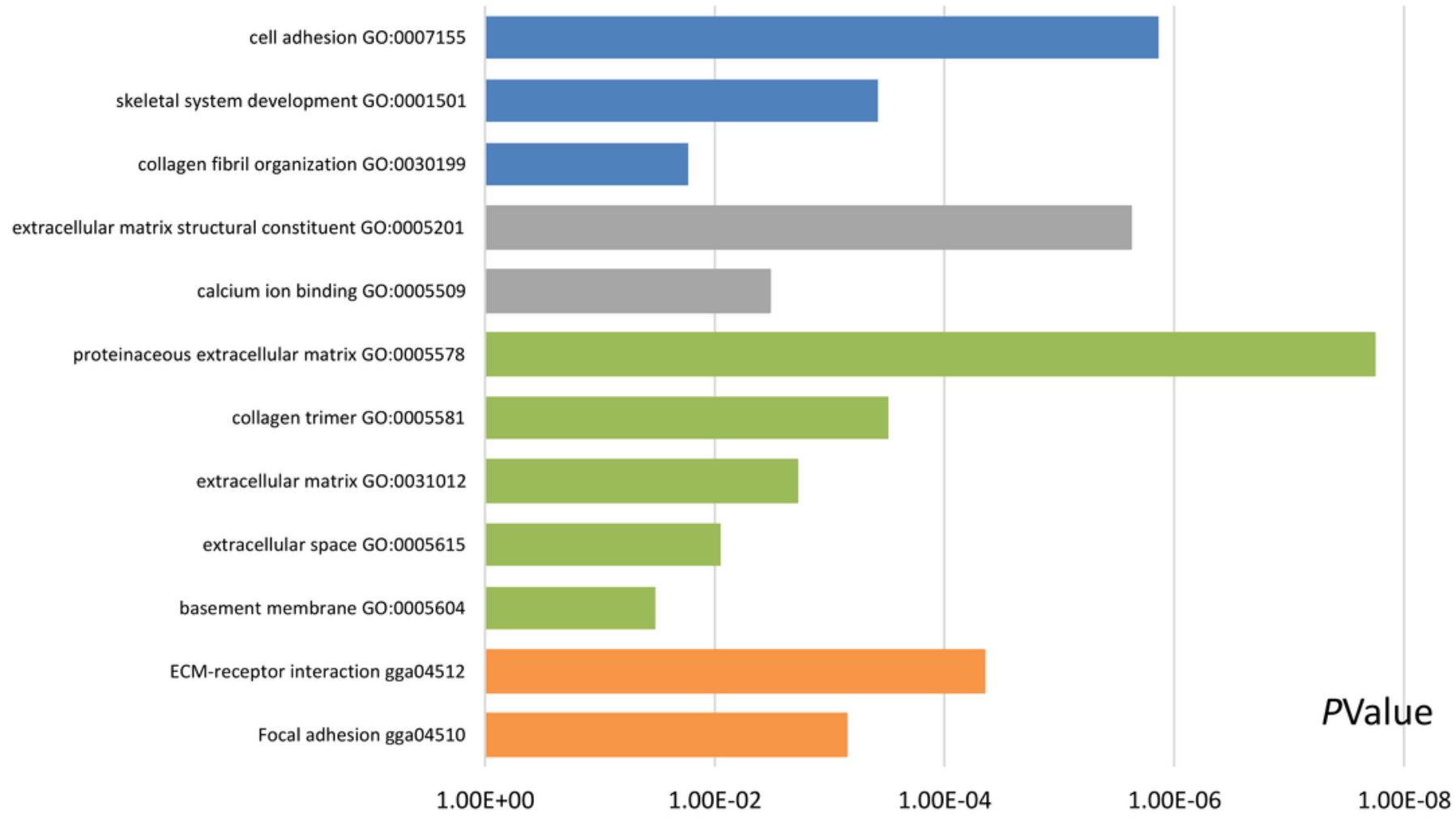


Figure 4

Results of GO and KEGG pathway analyses of 20 hub genes.

The blue color represents BP, the green color represents CC, the yellow color represents MF, and the orange color represents KEGG pathways.

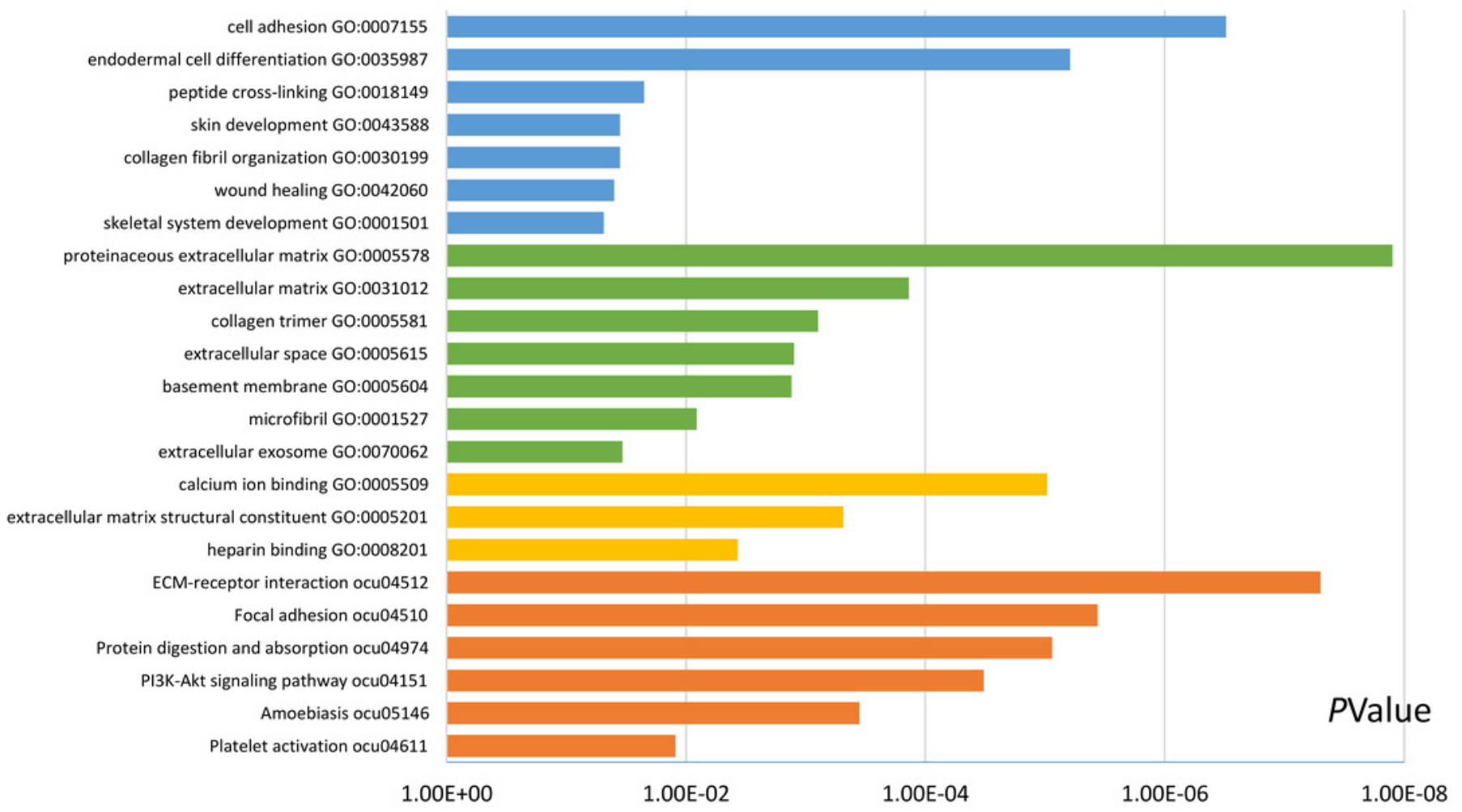


Figure 5

Overall survival analysis.

Overall survival curves for (A) COL12A1 and (B) MMP14 expression in PDAC patients in comparison with a high-risk group and a low-risk group. A value of $p<0.05$ was regarded as statistically significant. TPM = transcripts per million; $H R=$ hazards ratio.
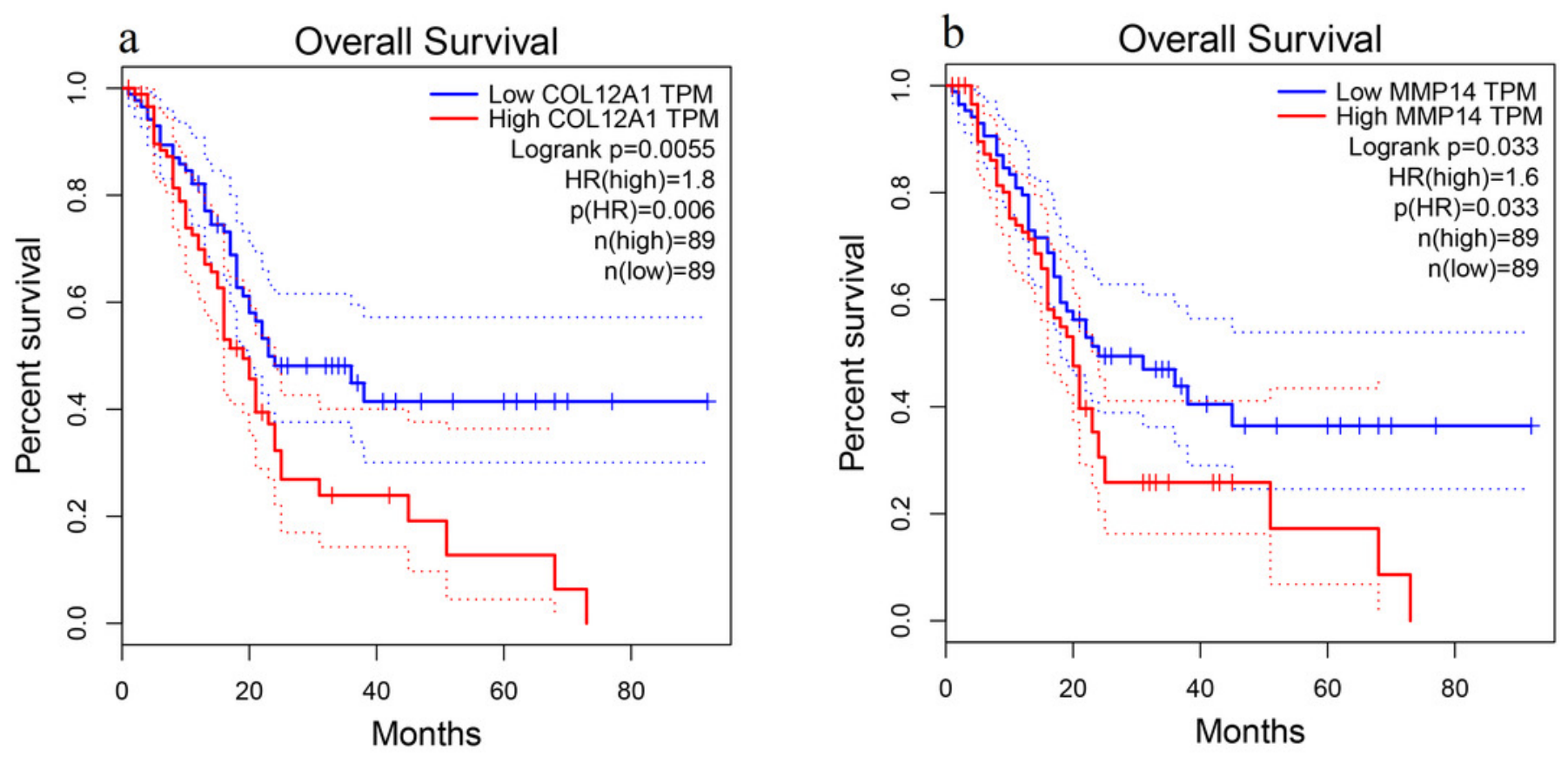


\section{Figure 6}

Validation of DEGs using The Cancer Genome Atlas and Genotype-Tissue Expression databases.

The boxplots were downloaded from the Gene Expression Profiling Interactive Analysis tool and are arranged in the following order: (A) FN1, (B) COLIA1, (C) COL3A1, (D) BGN, (E) POSTN, (F) FBN1, (G) COL5A2, (H) COL12A1, (I) THBS2, (J) COL6A3, (K) VCAN, (L) CDH11, (M) MMP14, (N) LTBP1, (O) IGFBP5, (P) FAP, (Q) MATN3, (R) COL8A1, and (S) ALB. A value of $p<$ 0.05 was regarded as statistically significant. The $Y$-axes represent the expression in terms of $\log _{2}(T P M+1)$. The red boxes represent the expression levels of DEGs in PAAD tissues, whereas the gray boxes represent the expression levels of DEGs in normal tissues. PAAD = pancreatic adenocarcinoma. 

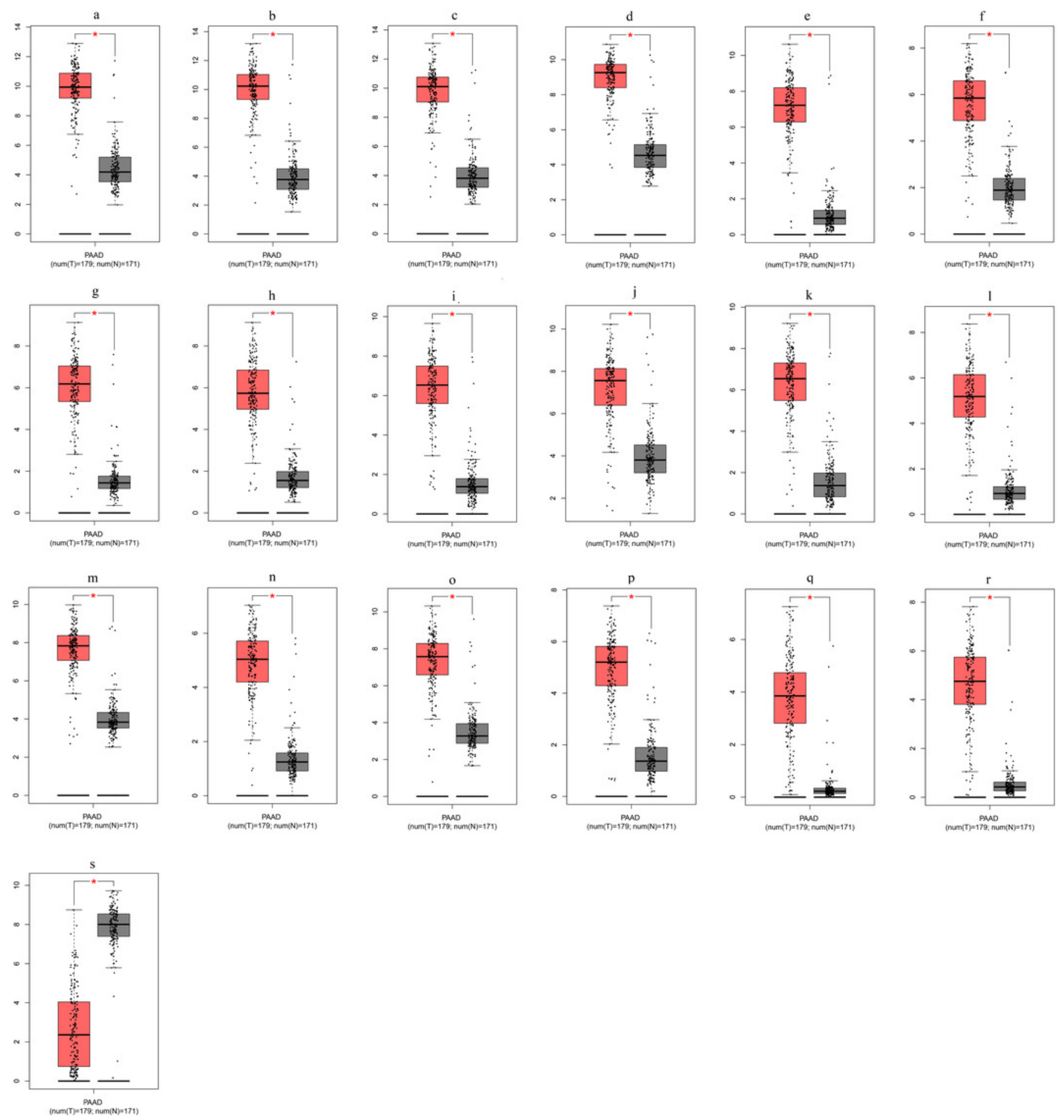


\section{Figure 7}

Expression of 20 candidate DEGs in human pancreatic cancer specimens.

The immunohistochemical data were obtained from the Human Protein Atlas. Except for COL5A2, IGFBP5, and MATN3, expression profiles of the other 17 genes in PDAC clinical specimens are shown. Staining demonstrated that the protein expressions of (A) FN1, (B) MMP14, (C) COL12A1, (D) COL3A1, (I) COL1A1, (L) FAP, (M) FBN1, (N) LTBP1, (O) POSTN, and (Q) VCAN were higher in PDAC tissues than in normal pancreatic tissues, with only (F) ALB being downregulated in PDAC tissues. (E) COL6A3, (H) CDH11, (J) COL8A1, and (K) CXCL12 were not expressed, whereas (G) BGN and (P) THBS2 were overexpressed in both PDAC tissues and normal tissues. 


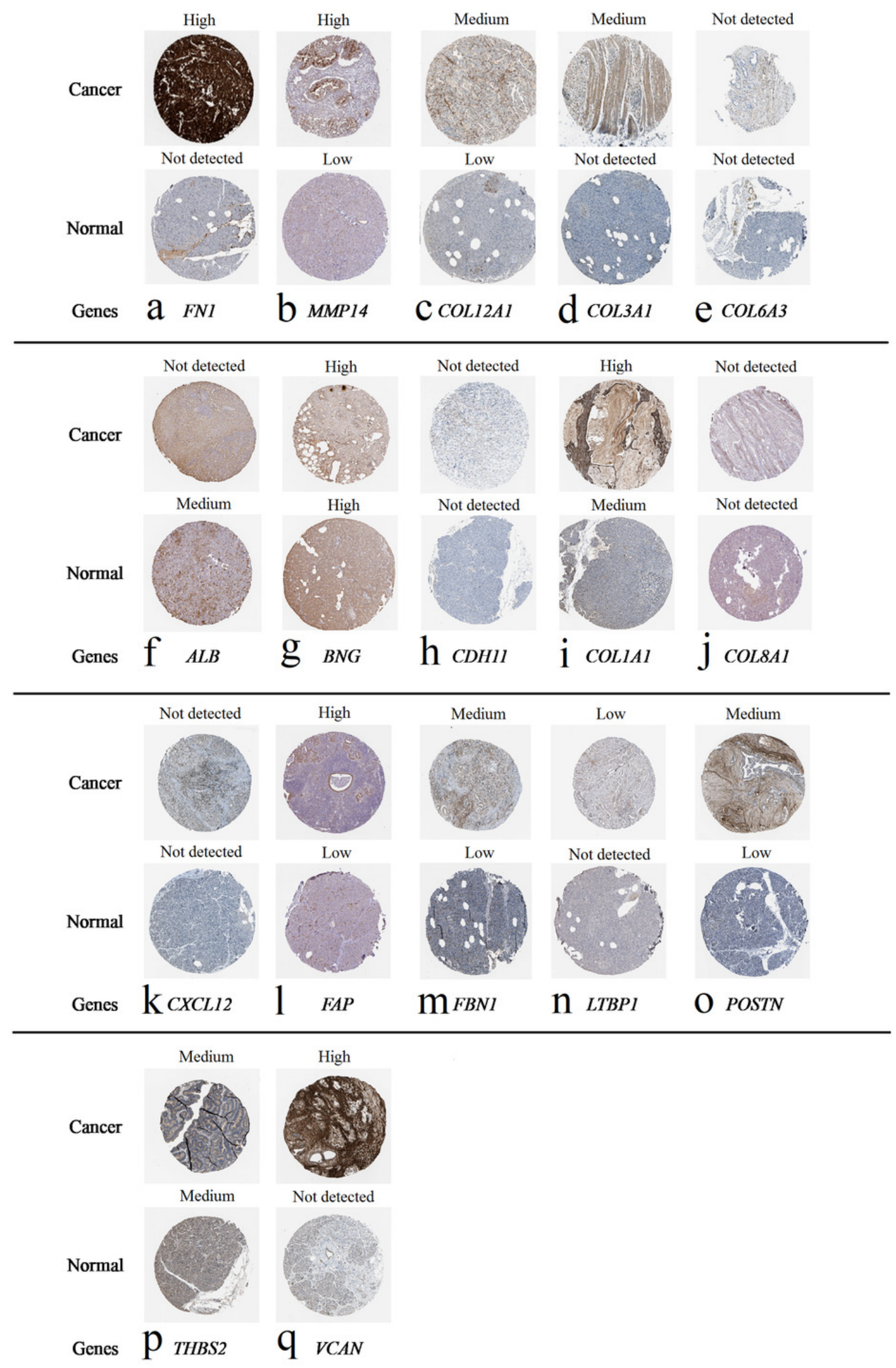




\section{Table $\mathbf{1}$ (on next page)}

A total of 263 DEGs were identified from the three microarray datasets, which consisted of 167 upregulated genes and 96 downregulated genes present in pancreatic ductal adenocarcinoma (PDAC) tissues in comparison with non-tumor tissues. 


\begin{tabular}{|c|c|}
\hline DEGs & Gene names \\
\hline $\begin{array}{l}\text { Upreg } \\
\text { ulated }\end{array}$ & 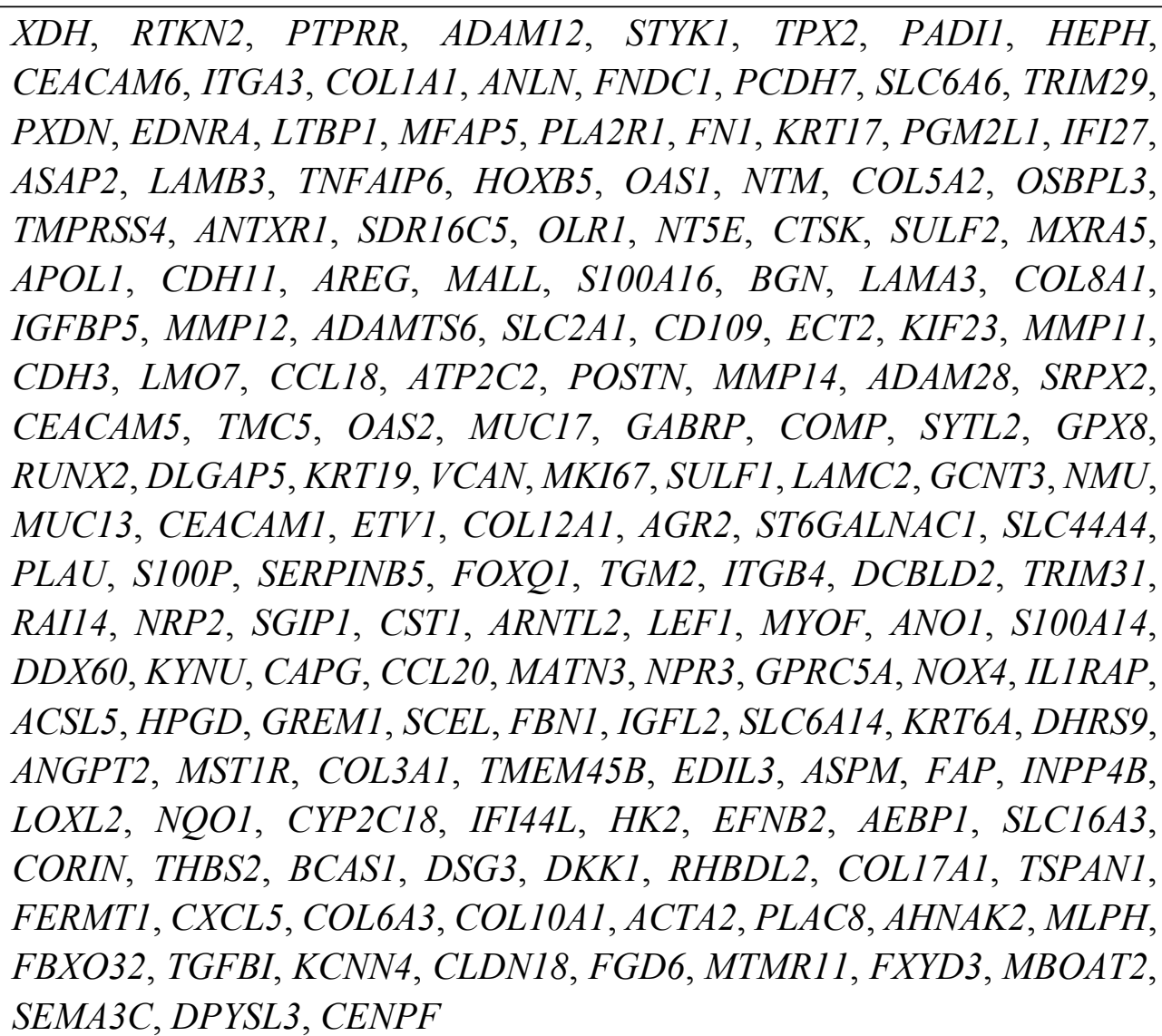 \\
\hline $\begin{array}{c}\text { Down } \\
\text { regula } \\
\text { ted }\end{array}$ & $\begin{array}{l}\text { EPB41L4B, GSTA2, KIAA1324, CELA3A, ACADL, CEL, SLC39A5, } \\
L O N R F 2, S L C 3 A 1, N R G 4, M T 1 G, P R O X 1, G 6 P C 2, C 5, E G F, F A M 3 B, \\
\text { AQP8, CLPS, SLC17A4, CPB1, GP2, PDK4, RBPJL, PDIA2, PM20D1, } \\
\text { CTRC, IAPP, PLA2G1B, ERP27, CELA2B, GRPR, REG1A, KIF1A, } \\
\text { GUCA1C, CTRL, SYCN, CHRM3, TMED6, ALB, KCNJ16, REG3A, } \\
\text { SLC4A4, AOX1, SERPINA5, CELA2A, SPINK1, FAM129A, FAM150B, } \\
\text { SLC16A12, F11, CPA2, SV2B, BNIP3, C2CD4B, SLC1A2, REG1B, SCGN, } \\
\text { PAK3, PRSS3, GRB14, REG3G, DCDC2,F8, GPHA2, EPHX2, PNLIPRP2, } \\
\text { SLC7A2, CPA1, PRKAR2B, ONECUT1, BACE1, NUCB2, HOMER2, } \\
\text { CXCL12, SLC43A1, GNMT, NR5A2, ALDH1A1, IL22RA1, BEX1, ANPEP, } \\
\text { CFTR, FLRT2, LMO3, FGL1, NRCAM, FABP4, PNLIPRP1, KLK1, } \\
\text { SERPINI2, GATM, DPP10, C6, SLC16A10, PRSS1, PAH }\end{array}$ \\
\hline
\end{tabular}


Table 2 (on next page)

Results of Gene Ontology (GO) and Kyoto Encyclopedia of Genes and Genomes (KEGG) pathway analyses of the most significant module. 


\begin{tabular}{|c|c|c|c|c|c|}
\hline $\begin{array}{l}\text { Pathway } \\
\text { ID }\end{array}$ & $\begin{array}{c}\text { Pathway } \\
\text { description }\end{array}$ & $\begin{array}{l}\text { Count in } \\
\text { gene set }\end{array}$ & $p$-value & FDR & DEGs \\
\hline GO:0007155 & cell adhesion & 5 & $1.37 \mathrm{E}-06$ & 0.001121514 & $\begin{array}{c}\text { COL6A3, } \\
\text { COL12A1, } \\
\text { VCAN, } \\
\text { POSTN, } \\
\text { THBS2 }\end{array}$ \\
\hline GO:0001501 & $\begin{array}{c}\text { skeletal } \\
\text { system } \\
\text { development }\end{array}$ & 3 & $3.80 \mathrm{E}-04$ & 0.310820683 & $\begin{array}{l}\text { FBN1, } \\
\text { VCAN, } \\
\text { COL5A2 }\end{array}$ \\
\hline GO:0030199 & $\begin{array}{c}\text { collagen } \\
\text { fibril } \\
\text { organization }\end{array}$ & 2 & 0.017003019 & 13.1195401 & $\begin{array}{c}\text { COL5A2, } \\
\text { CDH11 }\end{array}$ \\
\hline GO:0005201 & $\begin{array}{l}\text { extracellular } \\
\text { matrix } \\
\text { structural } \\
\text { constituent }\end{array}$ & 4 & $2.39 \mathrm{E}-06$ & 0.001487027 & $\begin{array}{c}\text { COL3A1, } \\
\text { FBN1, } \\
\text { VCAN, } \\
\text { COL5A2 }\end{array}$ \\
\hline GO:0005509 & $\begin{array}{l}\text { calcium ion } \\
\text { binding }\end{array}$ & 4 & 0.003312243 & 2.045566581 & $\begin{array}{l}\text { FBN1, } \\
\text { VCAN, } \\
\text { THBS2, } \\
\text { CDH11 }\end{array}$ \\
\hline GO:0005578 & $\begin{array}{c}\text { proteinaceous } \\
\text { extracellular } \\
\text { matrix }\end{array}$ & 6 & $1.81 \mathrm{E}-08$ & $1.29 \mathrm{E}-05$ & $\begin{array}{c}\text { COL3A1, } \\
\text { COL6A3, } \\
\text { FBN1, } \\
\text { COL12A1, } \\
\text { VCAN, } \\
\text { POSTN }\end{array}$ \\
\hline GO:0005581 & $\begin{array}{l}\text { collagen } \\
\text { trimer }\end{array}$ & 3 & $3.07 \mathrm{E}-04$ & 0.217600344 & $\begin{array}{l}\text { COL3A1, } \\
\text { COL6A3, } \\
\text { COL12A1 }\end{array}$ \\
\hline GO:0031012 & $\begin{array}{l}\text { extracellular } \\
\text { matrix }\end{array}$ & 3 & 0.001912518 & 1.350246354 & $\begin{array}{c}\text { FBN1, } \\
\text { COL12A1, } \\
\text { THBS2 }\end{array}$ \\
\hline GO:0005615 & $\begin{array}{l}\text { extracellular } \\
\text { space }\end{array}$ & 4 & 0.008881226 & 6.138544445 & $\begin{array}{c}\text { COL6A3, } \\
\text { FBN1, } \\
\text { COL12A1, } \\
\text { POSTN }\end{array}$ \\
\hline GO:0005604 & $\begin{array}{l}\text { basement } \\
\text { membrane }\end{array}$ & 2 & 0.032936583 & 21.16653102 & $\begin{array}{l}\text { FBN1, } \\
\text { THBS2 }\end{array}$ \\
\hline gga04512 & $\begin{array}{l}\text { ECM- } \\
\text { receptor }\end{array}$ & 4 & $4.51 \mathrm{E}-05$ & 0.019602271 & $\begin{array}{l}\text { COL3A1, } \\
\text { COL6A3, }\end{array}$ \\
\hline
\end{tabular}




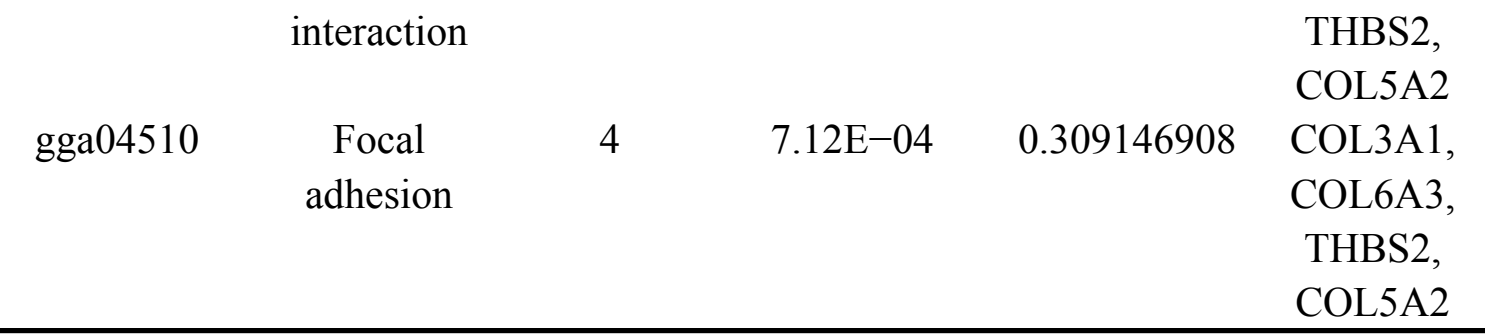

1 Abbreviation: FDR = false discovery rate. 
Table 3 (on next page)

Results of GO and KEGG pathway analyses of 20 hub genes. 


\begin{tabular}{|c|c|c|c|c|c|}
\hline $\begin{array}{l}\text { Pathway } \\
\text { ID }\end{array}$ & $\begin{array}{c}\text { Pathway } \\
\text { description }\end{array}$ & $\begin{array}{l}\text { Count in } \\
\text { gene set }\end{array}$ & $p$-value & FDR & DEGs \\
\hline GO:0007155 & cell adhesion & 6 & $3.07 \mathrm{E}-07$ & $3.44 \mathrm{E}-04$ & $\begin{array}{c}\text { COL12A1, } \\
\text { POSTN, } \\
\text { VCAN, } \\
\text { COL8A1, } \\
\text { THBS2, } \\
\text { FN1 }\end{array}$ \\
\hline GO:0035987 & $\begin{array}{l}\text { endodermal } \\
\text { cell } \\
\text { differentiatio } \\
\mathrm{n}\end{array}$ & 4 & $6.17 \mathrm{E}-06$ & 0.006927836 & $\begin{array}{l}\text { COL12A1, } \\
\text { MMP14, } \\
\text { COL8A1, } \\
\text { FN1 }\end{array}$ \\
\hline GO:0018149 & $\begin{array}{l}\text { peptide cross- } \\
\text { linking }\end{array}$ & 2 & 0.02230059 & 22.35847168 & $\begin{array}{l}\text { COL3A1, } \\
\text { FN1 }\end{array}$ \\
\hline GO:0043588 & $\begin{array}{c}\text { skin } \\
\text { development }\end{array}$ & 2 & 0.035457234 & 33.30840338 & $\begin{array}{l}\text { COL3A1, } \\
\text { COL5A2 }\end{array}$ \\
\hline GO:0030199 & $\begin{array}{c}\text { collagen fibril } \\
\text { organization }\end{array}$ & 2 & 0.035457234 & 33.30840338 & $\begin{array}{l}\text { COL3A1, } \\
\text { COL5A2 }\end{array}$ \\
\hline GO:0042060 & $\begin{array}{l}\text { wound } \\
\text { healing }\end{array}$ & 2 & 0.039805932 & 36.60570116 & $\begin{array}{l}\text { COL3A1, } \\
\text { FN1 }\end{array}$ \\
\hline GO:0001501 & $\begin{array}{c}\text { skeletal } \\
\text { system } \\
\text { development }\end{array}$ & 2 & 0.048448486 & 42.72191792 & $\begin{array}{l}\text { FBN1, } \\
\text { COL5A2 }\end{array}$ \\
\hline GO:0005578 & $\begin{array}{c}\text { proteinaceous } \\
\text { extracellular } \\
\text { matrix }\end{array}$ & 7 & $1.25 \mathrm{E}-08$ & $1.13 \mathrm{E}-05$ & $\begin{array}{c}\text { MATN3, } \\
\text { BGN, } \\
\text { FBN1, } \\
\text { COL12A1, } \\
\text { POSTN, } \\
\text { COL1A1, } \\
\text { FN1 }\end{array}$ \\
\hline GO:0031012 & $\begin{array}{l}\text { extracellular } \\
\text { matrix }\end{array}$ & 4 & $1.37 \mathrm{E}-04$ & 0.123843274 & $\begin{array}{c}\text { COL12A1, } \\
\text { VCAN, } \\
\text { MMP14, } \\
\text { COL8A1 }\end{array}$ \\
\hline GO:0005581 & $\begin{array}{l}\text { collagen } \\
\text { trimer }\end{array}$ & 3 & $7.87 \mathrm{E}-04$ & 0.70897958 & $\begin{array}{c}\text { COL12A1, } \\
\text { COL1A1, } \\
\text { COL8A1 }\end{array}$ \\
\hline GO:0005615 & $\begin{array}{l}\text { extracellular } \\
\text { space }\end{array}$ & 6 & 0.001248571 & 1.122732142 & $\begin{array}{c}\text { ALB, FAP, } \\
\text { COL3A1, } \\
\text { FBN1, } \\
\text { COL12A1, }\end{array}$ \\
\hline
\end{tabular}




\begin{tabular}{|c|c|c|c|c|c|}
\hline GO:0005604 & $\begin{array}{l}\text { basement } \\
\text { membrane }\end{array}$ & 3 & 0.001310663 & 1.178271997 & $\begin{array}{l}\text { VCAN } \\
\text { FBN1, } \\
\text { COL8A1, } \\
\text { THBS2 }\end{array}$ \\
\hline GO:0001527 & microfibril & 2 & 0.008113224 & 7.097635089 & $\begin{array}{c}\text { LTBP1, } \\
\text { FBN1 }\end{array}$ \\
\hline GO:0070062 & $\begin{array}{l}\text { extracellular } \\
\text { exosome }\end{array}$ & 7 & 0.033863185 & 26.75315613 & $\begin{array}{c}\text { BGN, ALB, } \\
\text { FBN1, } \\
\text { COL12A1, } \\
\text { COL8A1, } \\
\text { FN1, } \\
\text { CDH11 }\end{array}$ \\
\hline GO:0005509 & $\begin{array}{l}\text { calcium ion } \\
\text { binding }\end{array}$ & 7 & $9.57 \mathrm{E}-06$ & 0.007173793 & $\begin{array}{l}\text { MMP14, } \\
\text { MATN3, } \\
\text { LTBP1, } \\
\text { FBN1, } \\
\text { VCAN, } \\
\text { THBS2, } \\
\text { CDH11 }\end{array}$ \\
\hline GO:0005201 & $\begin{array}{l}\text { extracellular } \\
\text { matrix } \\
\text { structural } \\
\text { constituent }\end{array}$ & 3 & $4.84 \mathrm{E}-04$ & 0.362368483 & $\begin{array}{c}\text { COL3A1, } \\
\text { FBN1, } \\
\text { COL5A2 }\end{array}$ \\
\hline GO:0008201 & $\begin{array}{l}\text { heparin } \\
\text { binding }\end{array}$ & 3 & 0.003684116 & 2.728227814 & $\begin{array}{l}\text { POSTN, } \\
\text { THBS2, } \\
\text { FN1 }\end{array}$ \\
\hline ocu04512 & $\begin{array}{l}\text { ECM- } \\
\text { receptor } \\
\text { interaction }\end{array}$ & 6 & $5.00 \mathrm{E}-08$ & $4.15 \mathrm{E}-05$ & $\begin{array}{c}\text { COL3A1, } \\
\text { COL6A3, } \\
\text { COL1A1, } \\
\text { COL5A2, } \\
\text { THBS2, } \\
\text { FN1 }\end{array}$ \\
\hline ocu04510 & $\begin{array}{c}\text { Focal } \\
\text { adhesion }\end{array}$ & 6 & $3.64 \mathrm{E}-06$ & 0.003011517 & $\begin{array}{c}\text { COL3A1, } \\
\text { COL6A3, } \\
\text { COL1A1, } \\
\text { COL5A2, } \\
\text { THBS2, } \\
\text { FN1 }\end{array}$ \\
\hline ocu04974 & $\begin{array}{c}\text { Protein } \\
\text { digestion and } \\
\text { absorption }\end{array}$ & 5 & $8.69 \mathrm{E}-06$ & 0.007197854 & $\begin{array}{l}\text { COL3A1, } \\
\text { COL6A3, } \\
\text { COL12A1, }\end{array}$ \\
\hline
\end{tabular}




\begin{tabular}{|c|c|c|c|c|c|}
\hline & & & & & COL1A1, \\
\hline ocu04151 & $\begin{array}{l}\text { PI3K-Akt } \\
\text { signaling } \\
\text { pathway }\end{array}$ & 6 & $3.26 \mathrm{E}-05$ & 0.026969277 & $\begin{array}{c}\text { COL3A1, } \\
\text { COL6A3, } \\
\text { COL1A1, } \\
\text { COL5A2, } \\
\text { THBS2, } \\
\text { FN1 }\end{array}$ \\
\hline ocu05146 & Amoebiasis & 4 & $3.54 \mathrm{E}-04$ & 0.292970736 & $\begin{array}{c}\text { COL3A1, } \\
\text { COL1A1, } \\
\text { COL5A2, } \\
\text { FN1 }\end{array}$ \\
\hline ocu04611 & $\begin{array}{c}\text { Platelet } \\
\text { activation }\end{array}$ & 3 & 0.012199259 & 9.669074187 & $\begin{array}{l}\text { COL3A1, } \\
\text { COL1A1, } \\
\text { COL5A2 }\end{array}$ \\
\hline
\end{tabular}

1 